\title{
Mudanças climáticas, educação e meio ambiente: para além do Conservadorismo Dinâmico
}

\section{Climate change, education and environment: beyond Dynamic Conservatism}

\author{
Gustavo Ferreira da Costa Lima ${ }^{1}$ \\ Philippe Pomier Layrargues ${ }^{2}$
}

\begin{abstract}
RESUMO
O presente ensaio discute a crise climática contemporânea e as possibilidades de inserção da educação ambiental neste debate. Trata-se de um diálogo com a produção da área, com os pressupostos da Ecologia Política, da Educação ambiental crítica, do pensamento da Complexidade e da Sociologia de Risco de Giddens e Beck. O artigo entende que, apesar das relativas incertezas que ainda cercam o debate sobre as mudanças climáticas, elas se configuram como o principal problema ambiental global contemporâneo. Pesquisas evidenciam a intensidade dos eventos climáticos extremos em todo o mundo e seus efeitos danosos sobre a saúde, o bem-estar público, a segurança alimentar e os patrimônios ambientais e sociais. No entanto, a invisibilidade do problema na vida cotidiana, a ação das controvérsias e dos lobbies econômicos, a inércia dos governos e das instituições relacionadas ao tema têm mostrado que a formulação de respostas eficientes sobre o impasse climático não tem acompanhado o aumento da consciência pública sobre este problema. Que conjunção de fatores justifica esse paradoxo? Este artigo argumenta que o atual debate tem sido pautado por argumentos e respostas reducionistas, tecnicistas e conservadoras - o Conservadorismo Dinâmico - que não dão conta de compreender o problema em toda a sua
\end{abstract}

DOI: $10.1590 / 0104-4060.38108$

1 Universidade Federal da Paraíba. Departamento de Ciências Sociais. Programa Regional de Pós-Graduação em Desenvolvimento e Meio Ambiente. João Pessoa, Paraíba, Brasil. Cidade Universitária, s/n. Castelo Branco. CEP: 58051-900.

2 Universidade de Brasília Planaltina. Brasília, Distrito Federal, Brasil. Área Universitária, 01, Vila Nossa Senhora de Fátima. Planaltina. CEP: 73345-010. 
complexidade e, portanto, de formular estratégias capazes de revertê-lo ou de minimizar seus impactos. Entende-se, portanto, que a educação ambiental pode contribuir com esse esforço para renovar a compreensão do problema e a ação dos indivíduos, das instituições e dos agentes públicos e privados envolvidos com o tema.

Palavras-chave: mudanças climáticas; educação ambiental; complexidade.

\begin{abstract}
The current essay discusses the contemporary climate crisis and the possibilities of inserting environmental education in this debate. It refers to an interface between the theme research and theoretical assumptions of Political Ecology, Critical environmental education, Complexity thinking and Giddens' and Beck's Risk Sociology. The article affirms that besides relative uncertainties that still surround climate change debates, they constitute the main global contemporary environmental problem. A lot of studies show the intensity and frequency of extreme climatic events all over the world and its harmful effects on health, public welfare, food safety and environmental and social heritage. However, the problem invisibility in daily life, the effects of controversies and economic lobbies, the inertia of governments and institutions related to this theme have shown that formulating effective responses to the climatic impasse has not followed the increasing public awareness on this problem. What set of factors justifies this paradox? This article assumes that current debates have been guided by reductionist, technicalist and conservative responses - the Dynamic Conservatism - that are not able to understand the problem in its whole complexity and, therefore, of formulating strategies capable to reverse it or, at least, to minimize its potential impacts. It considers, therefore, that environmental education can contribute with this effort of renewing the problem understanding and the actions of individuals, institutions and other public and private actors involved with that issue.
\end{abstract}

Keywords: climate change; environmental education; complexity.

\title{
Introdução
}

O fenômeno das mudanças climáticas ocupa atualmente o centro da agenda ambiental mundial e atravessa inevitavelmente todas as demais agendas políticas, econômicas, sociais e culturais que conformam o desenvolvimento e a gestão das sociedades contemporâneas. Esse interesse se justifica pelos im- 
pactos já produzidos pelos eventos climáticos extremos, pelos riscos previstos em diversas áreas estratégicas da vida humana como oferta de água e energia, segurança alimentar, saúde pública, sustentabilidade urbana, migrações, biodiversidade e produção econômica. Causa preocupação adicional porque atinge principalmente os setores mais vulneráveis da população, porque dificulta o combate à pobreza já existente e porque implica em uma urgência temporal que cresce com o aquecimento assim como os custos para intervir sobre o problema (IPCC, 2007; MARENGO, 2008; GIDDENS, 2010).

Neste contexto, o presente artigo se organiza como um ensaio que discute a complexidade do fenômeno das mudanças climáticas, as possíveis contribuições da educação para o seu equacionamento e as principais respostas presentes e ausentes do debate sobre o tema.

$\mathrm{O}$ argumento que atravessa o texto parte da premissa de que as respostas mais visíveis ao problema nos meios políticos, midiáticos e, em parte da comunidade científica, tendem ao reducionismo e estão aquém do desafio em curso, expressando uma posição que Schon (1973) e Guimarães (1995) denominaram de "Conservadorismo Dinâmico". Para Guimarães, o Conservadorismo Dinâmico é "a tendência inercial do sistema para resistir à mudança, promovendo a aceitação do discurso transformador para garantir que nada mude" (1995, p. 118). Essa posição consegue ser mais danosa ao debate e busca soluções com base no Conservadorismo convencional porque cria um conjunto de respostas paliativas e simula um encaminhamento do problema que é incapaz de revertê-lo em sua complexidade e porque resulta na desmobilização e na despolitização dos atores nele envolvidos. Ou seja, aceitos os argumentos do Intergovernmental Panel on Climate Change (IPCC) de que a crise climática tem origem antropogênica e resulta do modelo de desenvolvimento, produção e consumo praticado pelas sociedades humanas desde a revolução industrial, é sensato concluir que sejam necessárias respostas abrangentes nas múltiplas dimensões do sistema responsável pela crise e não apenas reformas pontuais e setoriais para reverter ou minimizar o curso dos impactos já verificados e os graves riscos estimados para o futuro próximo. Essa constatação distingue a percepção da crise ambiental como desafio civilizatório ou como um problema de gestão meramente técnica. A presente reflexão adota o primeiro diagnóstico ao reconhecer a multidimensionalidade das crises ambiental e climática e investiga as possibilidades e limites de construção de uma sustentabilidade alternativa que seja plural e democrática. Para efeito de ilustração, consideram-se respostas atreladas ao Conservadorismo Dinâmico as que entendem que a ecoeficiência tecnológica, por si só, será capaz de promover o desacoplamento entre produção, energia e recursos naturais; os mecanismos de mercado de carbono criados ou propostos no âmbito do Protocolo de Kyoto como o Mecanismo de Desenvolvimento Limpo - MDL e a Redução 
de Emissão por Desmatamento e Degradação - REDD; as iniciativas pautadas no consumo verde e no marketing ambiental; a defesa da transgenia na agricultura como solução para o desafio alimentar; o ambientalismo preservacionista das grandes ONGs internacionais em sua dissociação entre os problemas ecológicos e sociais e a aposta irrestrita nos biocombustíveis e na energia nuclear como soluções à questão energética. Ressalte-se que não se trata de desqualificar as diversas propostas de combate ou minimização da crise climática, mas de discutir seus limites ante a dimensão do problema considerado, sobretudo, quando são pensadas como soluções isoladas ou como formas de evitar mudanças mais abrangentes na ordem sistêmica instituída pelo capitalismo.

Para cumprir seu objetivo o artigo dialoga com a produção da área e com elementos da Ecologia Política, da Educação Ambiental Crítica, do Pensamento da Complexidade e da Sociologia de Risco formulada por Ulrich Beck e Anthony Giddens. Esses referenciais se justificam pelo interesse em incorporar à reflexão a diversidade de conflitos socioambientais que o problema evoca, pela multidimensionalidade e incerteza que compõe sua complexidade, pela necessidade de problematizar pedagogicamente a relação sociedade-ambiente e a crise climática em seu interior e pela inevitabilidade de reconhecer os novos riscos sociais e tecnológicos que permeiam a vida contemporânea e que ameaçam continuamente a capacidade de controle e de resposta das instituições modernas (LIPIETZ, 2002; LITTLE, 2006; MORIN, 1996; LIMA, 2009b; CARVALHO, 2004; BECK, 1992; GIDDENS, 1991).

Com os propósitos anunciados, o artigo se organiza em três momentos analíticos além desta introdução: uma primeira seção, que discute a complexidade e os desafios colocados pela crise climática; uma segunda, que trata das contribuições e dos limites dos processos educativos na formação e transformação dos indivíduos, dos conhecimentos existentes sobre o problema e dos modos de perceber, reagir e conviver com as policrises contemporâneas, além de uma seção de considerações finais onde se exercita a síntese e os resultados da reflexão realizada.

\section{A complexidade da crise climática e os desafios abertos}

A complexidade da crise climática reflete seu caráter global; a interação, muitas vezes conflitiva de um conjunto de elementos políticos, econômicos, sociais, ecológicos, educacionais, tecnológicos, comunicativos, ético-culturais e epistemológicos; reduzida vontade política para intervir e assumir com- 
promissos e uma relativa dose de incerteza no conhecimento existente que favorece a controvérsia com os opositores, a confusão e a inércia da opinião pública. Estas características tipificam-na como uma crise multidisciplinar, de alta complexidade e de relevante interesse público porque implica em riscos sociais globais, em especial para as populações mais vulneráveis socialmente. Essa conformação, portanto, não aceita respostas reducionistas e monodimensionais em sua abordagem.

Esta seção discute alguns dos elementos que conformam a crise climática com destaque para os obstáculos político-econômicos, o ambiente de relativa incerteza e de controvérsias que contaminam a comunicação e a educação, favorecendo a inércia do público e os valores e crenças culturais que retardam a mudança desejada. Importa considerar na análise que, embora os elementos mencionados se distingam didaticamente, na prática interagem e se cruzam entre si criando novas implicações e retroalimentações (feedbacks) inesperadas que merecem atenção.

\section{Os obstáculos políticos e econômicos}

Os obstáculos políticos e econômicos tiveram e continuam tendo um papel determinante na formação da crise climática e também na busca de solução ou atenuação do problema. Historicamente foram determinantes porque constituíram o modelo de desenvolvimento, produção e consumo das economias ocidentais que está na gênese do aquecimento e continuam sendo elementos prioritários porque é do núcleo econômico-político que podem emanar as decisões e estratégias de reversão ou mitigação do problema. Ou seja, é nesse ponto que os macroatores econômicos como as grandes corporações globais, financeiras ou produtivas e os Estados nacionais, em especial, os mais ricos, assumem posições e comportamentos conservadores em defesa de seus interesses particulares, da rentabilidade de seus investimentos e da manutenção de sua competitividade na economia e geopolítica globais (VIOLA, 2012). Assim, os debates sobre os custos e responsabilidades sobre a redução de emissões, a mitigação e adequação frente às mudanças climáticas; sobre o desenvolvimento e a transferência de tecnologias limpas; sobre os investimentos para a transição e adaptação energética, dos transportes e da agricultura; sobre o perfil e alcance das políticas públicas nacionais e internacionais; sobre o papel e o poder de mediação dos organismos internacionais; sobre a resistência e recusa das maiores potências em assumir compromissos formais; como também sobre os setores potencialmente favorecidos pela crise e catástrofes climáticas são permeados por conflitos que tendem a travar as negociações e as perspectivas de avançar sobre soluções efetivas. 
A fragilização do Estado-Nação no processo de globalização neoliberal, que se expandiu a partir dos anos 1980, reduziu o poder de regulação e o protagonismo dos governos na formulação de políticas e na intervenção em áreas pouco atraentes à iniciativa privada. Favoreceu também por omissão o uso de mecanismos de mercado como respostas à inércia dos Estados. O efeito foi particularmente regressivo sobre as políticas públicas e sociais voltadas à saúde, à educação, ao meio ambiente e ao combate à pobreza (SUNKEL, 1999).

Por outro lado, a carência ou insuficiência de organismos internacionais capazes de mediar as relações entre as nações e destas com as grandes corporações sobre questões globais, como é o caso do aquecimento global, é outra lacuna importante nesse processo. A Organização das Nações Unidas - ONU e demais organismos supranacionais são os únicos recursos políticos disponíveis, mas devido às assimetrias de poder no cenário mundial têm se revelado claramente insuficientes nos momentos de crise ${ }^{3}$. Assim, como conseguir a cooperação de todos os países, ou ao menos da maioria deles sem instrumentos legais e coercitivos abrangentes, legítimos e igualmente válidos para todos? Como arbitrar questões ambientais transfronteiriças ou que envolvam conflitos de interesse entre nações, sobretudo, quando estão em jogo disputas entre contendores dotados de forças desiguais? (LEIS, 1995).

Em anos recentes grandes potências e emissores como os Estados Unidos e a China têm se recusado a liderar e mesmo a cooperar com as políticas de redução do carbono porque têm prioridades outras ligadas à defesa de sua soberania e competitividade econômica, a compromissos com os lobbies das indústrias de energia ou ainda por entender, no caso da China, que essa liderança cabe aos norte-americanos que detêm tanto superioridade econômica quanto um percentual de emissões per capita acima dos seus. No caso da Europa, ainda que historicamente tenham feito maiores esforços na transição para uma economia de baixo carbono, a crise econômica que atingiu o continente desde 2010, com a expansão desproporcional da dívida pública de diversos países da União e, que persiste desde então, tem relegado as questões do clima para um plano secundário (VIOLA, 2012; SACHS, 2010).

$\mathrm{O}$ modelo de produção e consumo de massa, baseado em tecnologias poluentes, intensivo em combustíveis fósseis e no uso de recursos naturais e moldado no "American way of life" 4 é reconhecidamente insustentável e torná-lo algo próximo do sustentável exige mudanças profundas, algumas das quais contrárias à lógica do capital. É, portanto, um desafio central na presente crise,

3 Vide o conflito entre os Estados Unidos e a ONU por ocasião da última invasão do Iraque em 2003, resolvido em favor dos norte-americanos pelo simples argumento da força política-militar.

4 Estilo de vida norte-americano. 
quando se considera a necessidade de reduzir emissões de carbono, de reconhecer os limites do crescimento e as desigualdades sociais internacionais e internas a cada país e de constatar que, embora a inovação tecnológica tenha avançado na redução relativa do uso de energia e recursos naturais necessários à produção econômica de bens e serviços, ela não é capaz de conter o crescimento absoluto no uso destes insumos decorrente do crescimento populacional e do aumento do consumo global, seja por parte das populações dos países emergentes incluídas recentemente no mercado consumidor, seja por parte do alto consumo dos habitantes dos países mais ricos. Isso faz com que a pressão absoluta sobre o ambiente e os ecossistemas siga crescendo e obriga os pesquisadores e gestores envolvidos com a temática a considerarem outros aspectos do problema como: a reedição dos alertas sobre os limites do crescimento, a redução do consumo dos mais ricos, a reversão dos mecanismos de obsolescência planejada, o uso de instrumentos econômicos de contenção do consumo, a descarbonização da matriz energética, a transferência de tecnologias limpas dos países centrais para os periféricos, a redução do desperdício associada ao aumento da reciclagem de materiais, o uso de bens e serviços coletivos em lugar dos individuais e por último, ainda que não menos importante, as mudanças nos padrões e nas atitudes dominantes de consumo na vida contemporânea (HARVEY, 2012). Dos fatores elencados alguns são mais factíveis e já estão se processando ainda que não no ritmo desejado, outros de natureza educativa e valorativa, de relevância central na presente análise, exigem mais tempo e criatividade e aqueles que implicam conflitos mais diretos com a racionalidade do capital ou com interesses consolidados na ordem econômico-política são mais difíceis de prever se, e quando, entrarão na agenda climática. A crença otimista na ecoeficiência tecnológica, portanto, ainda que tenha testemunhado avanços significativos na busca de produzir mais com menos recursos naturais, energia, emissões de carbono e geração de lixo não é capaz de isoladamente responder ao desafio da crise climática sem incorporar, como quer Abramovay (2012), as ideias de limites e de desigualdades do consumo entre nações e no interior de cada uma delas. Essa constatação levou o autor a afirmar em outro momento: "Sistemas de inovação voltados para a sustentabilidade são fundamentais. Mas achar que eles permitirão suprimir os limites é exprimir uma crença mística no poder da técnica que a ciência não autoriza e a ética não recomenda" (ABRAMOVAY, 2012).

\section{O conhecimento, as incertezas e a percepção do público}

O segundo elemento estruturador da complexidade da crise climática diz respeito ao conhecimento existente sobre o fenômeno, à comunicação e interpretação do mesmo e à percepção final do público. Ainda que o trabalho do 
IPCC - Painel Intergovernamental sobre Mudanças Climáticas tenha convergido para um consenso amplo sobre o estado da arte do aquecimento, alguma dose de incerteza ainda persiste, sobretudo com relação à intensidade dos impactos estimados, sua localização e temporalidade. Essa incerteza relativa, apesar de diminuta $^{5}$, tem dado margem a controvérsias entre as posições do IPCC que afirmam a crise climática e sua origem antropogênica e a de grupos e autores céticos que entendem o aquecimento como um fenômeno natural sobre o qual não temos responsabilidade nem podemos intervir. A escassa incerteza também tem favorecido a presença no debate de lobbies contrários à posição do IPCC ligados a empresas poluidoras e potencialmente prejudicadas numa eventual descarbonização do modelo econômico, como é o caso dos setores de energia fóssil, como petróleo e carvão e todos os setores intensivos em carbono como as indústrias químicas, petroquímicas, siderúrgicas, de alumínio, de aço, de celulose e papel, mineradoras, de cimento, madeireiras e as empresas ligadas ao complexo agropecuário, entre outras. $\mathrm{O}$ efeito conjunto das controvérsias negacionistas, das mensagens e discursos dos lobbies anticlima, da comunicação midiática comprometida e distorcida por tais posições e a própria invisibilidade do problema na vida cotidiana são a confusão, a perplexidade e a inércia do público em geral, outro ponto onde a ação educativa pode oferecer grande contribuição.

Para Giddens (2010), essa invisibilidade do risco constitui o paradoxo que nos induz à inércia e à passividade ainda que a espera para que as consequências dos problemas amadureçam e se tornem visíveis tornará as respostas para sua reversão tardias. Ou seja, não reagimos porque não percebemos o problema com clareza, mas se formos esperar que ele se torne visível já será tarde demais.

\section{Os valores culturais hegemônicos}

O terceiro elemento elencado sobre a complexidade das mudanças climáticas são os valores e crenças culturais hegemônicas que induzem a civilização numa direção contrária à que o contexto de aquecimento e das pesquisas científicas, em sua maioria, tem recomendado. Faz-se aqui referência à prevalência no plano cultural das ideias de crescimento econômico e progresso; ao consumo como componente indissociável na constituição da identidade e da subjetividade do sujeito contemporâneo e na concepção dominante da felicidade nas sociedades pós-industriais. Esses elementos culturais, encravados no ethos

5 Pesquisas recentes têm demonstrado que apesar do barulho que fazem no debate e nas mídias os argumentos céticos são amplamente minoritários. O pesquisador John Cook da Universidade de Queensland na Austrália constatou, em levantamento de 12 mil artigos das duas últimas décadas sobre o tema, que apenas $1 \%$ (um por cento) do total dos artigos respaldam a posição de que as mudanças climáticas são desvinculadas das atividades humanas. 
capitalista, articulam os planos material e simbólico da realidade e parecem ser simultaneamente os motores e os algozes do percurso recente da civilização contemporânea. E, justamente seu papel decisivo no processo de reprodução do capital e na sedução da subjetividade humana - ampliados pelos artifícios mercadológicos - é que faz o desafio de sua desconstrução. Ou seja, como desmontar o mito do crescimento e a idealização dos estilos de vida dos países ricos do norte? Como distinguir felicidade, consumo e cidadania e descobrir novas possibilidades de realização humana? Os teóricos do Decrescimento, do Pós-desenvolvimento e da Economia Ecológica têm discutido o tema a partir da reflexão sobre a herança histórica das experiências de desenvolvimento no contexto das mudanças climáticas e das incertezas futuras. Naturalmente que não há respostas fáceis a esses desafios, mas a responsabilidade ética nos obriga a encará-los e a procurar respostas capazes de confrontá-los obedecendo a critérios de complexidade, precaução e convivência democrática. Esses estudos, ainda que diversos, têm reconhecido a dificuldade, senão a impossibilidade, de conter as crises ambientais e climáticas sem impor limites ao crescimento e aos padrões de consumo dominantes nas sociedades pós-industriais (LATOUCHE, 2012; ESCOBAR, 2005; DALY, 1999).

Os impactos verificados e estimados da crise climática têm demonstrado que a manutenção das tendências atuais de emissões de carbono, expansão demográfica e de consumo e de uso de tecnologias "sujas" ameaça severamente a segurança das sociedades humanas com riscos de disrupções incontornáveis (VIOLA, 2012; ROCKSTRÖM, 2009). Essa constatação reafirma o argumento de que as respostas reducionistas ou paliativas ao problema, como as norteadas pelo Conservadorismo Dinâmico, não serão capazes de reverter a magnitude da crise em questão.

\section{A contribuição possível da educação}

À luz do diagnóstico construído sobre a crise climática é possível perceber as brechas onde o potencial da educação pode se inserir e produzir resultados de médio e de longo prazos. Ela pode, por exemplo, imprimir um olhar complexo ao problema, nem sempre presente nas análises mais apressadas; pode agregar informação de qualidade à comunicação pública, dirimir falsas controvérsias e com isso facilitar a inclusão do educando no debate em curso, em ações cotidianas e na participação em movimentos orientados à questão climática. Enfim, os processos educativos podem ampliar a compreensão do fenômeno climático, de 
sua gênese histórica, de suas causas estruturantes, de suas múltiplas dimensões, em especial as condicionantes políticas e culturais menos aparentes e das alternativas de sua superação, disponíveis para os indivíduos, grupos, movimentos sociais, empresas e governos.

Sabe-se que a educação não atua diretamente sobre os problemas sociais, mas indiretamente sobre a consciência dos indivíduos e de sua capacidade de atribuir significados às relações sociais, à relação entre a sociedade e o ambiente e de agir de acordo com os sentidos construídos. Por cumprirem funções de mediação e de interpretação do real, a educação e os educadores podem assumir diversas concepções e práticas educativas que oscilam entre a reprodução e a transformação do status quo, entre a mono e a multidimensionalidade, entre o estímulo à autonomia e a heteronomia do educando, entre o reducionismo e a complexidade, entre a crítica e o conformismo. Esses "tipos ideais" ${ }^{6}$ não pretendem estabelecer dicotomias maniqueístas no interior do campo da educação ambiental, mas apenas representar a multiplicidade de tendências político-pedagógicas que disputam entre si os sentidos e a hegemonia do campo e o poder de conduzi-lo de acordo com sua interpretação da realidade (BOURDIEU, 2004; LAYRARGUES; LIMA, 2014). Nesse sentido, a presente defesa de superação do "Conservadorismo Dinâmico" entende que a magnitude da crise climática exige saídas políticas e educativas transformadoras capazes de perceber toda a complexidade do problema, de avaliá-lo com criticidade e de compreender os conflitos políticos e os dilemas ético-valorativos envolvidos na questão.

Com esse referencial crítico e complexo é possível construir processos educativos que valorizem a práxis, entendida como a articulação entre teoria e prática; a atuação simultânea nos planos da educação formal e não formal; a aproximação do nível local, comunitário e cotidiano; a interdependência entre as ações individuais (na esfera privada) e as ações sociais (na esfera pública) e a ampliação da cidadania e da democracia participativa como meios de regular e de democratizar o papel do Estado e das empresas frente aos desafios ambientais e climáticos (FREIRE, 2003; HABERMAS, 1986; GOHN, 2006).

No contexto analisado, a proposta de uma educação práxica supõe o avanço na compreensão teórica do problema e o estímulo à construção de ações transformadoras capazes de romper com a inércia atual e de estabelecer conexões entre o desafio climático e a vida cotidiana.

No plano teórico, trata-se de problematizar: a origem histórica do aquecimento e das mudanças climáticas; os condicionantes globais e locais de sua

6 Para Max Weber os tipos ideais, embora se inspirem na observação da realidade, não têm uma correspondência no mundo objetivo. São antes recursos analíticos abstratos construídos como referências aproximativas que ajudam a compreender a realidade (GIDDENS, 2005). 
ocorrência; as consequências presentes e os riscos estimados; a avaliação dos conhecimentos existentes e divulgados nos meios de comunicação; os diferentes pontos de vista sobre o tema e principais convergências e divergências; os conflitos, interesses e responsabilidades dos atores envolvidos; a relação do problema com os padrões de consumo, estilos de vida e os valores hegemônicos na sociedade e as alternativas disponíveis de reversão, mitigação e adaptação ao fenômeno. Importa ressaltar que nessa problematização do tema a pedagogia de projetos é um instrumento valioso porque permite: a) articular a escola e o currículo com os problemas socioambientais; b) exercitar a pesquisa e a construção coletiva do conhecimento; c) facultar ao aluno o aprendizado pela experiência; d) estimular a autonomia e o pensamento crítico; e) experimentar a transversalidade do saber; além de: f) abrir ao aluno e à escola o contato com a comunidade e os problemas locais.

Quanto às alternativas práticas, o processo educativo pode fomentar: campanhas de esclarecimento da opinião pública; parcerias entre as escolas, as comunidades do entorno e outros setores da sociedade civil organizada; ações de cobrança das autoridades constituídas no cumprimento de suas responsabilidades legais e na aplicação das leis ambientais existentes; experiências de trabalhos voluntários como dias de campo, plantio de árvores, recuperação de matas ciliares, canteiros de mudas, coletas de lixo, oficinas de compostagem, hortas comunitárias, projetos e oficinas pedagógicas para monitorar o clima, a qualidade das águas, do ar, das florestas e parques locais, mas também demonstrar a necessidade e os meios de reduzir a produção de resíduos sólidos e o desperdício de recursos naturais.

Há, portanto, um duplo desafio que consiste em, por um lado, ampliar a compreensão crítica do fenômeno e, por outro lado, tomar consciência das possibilidades de ação individuais e coletivas na vida cotidiana.

Vimos anteriormente que, apesar das diferenças que caracterizam os processos educativos formais e não formais, há possibilidades educativas complementares entre os dois planos. No plano formal, trata-se de conjugar os conteúdos indicados na dimensão teórica da educação no interior de um currículo mais amplo que contemple a relação entre a sociedade e o ambiente com outras ações práticas como a gestão democrática da escola e a adaptação do espaço físico conforme os princípios e experiências do que tem se denominado de "Escolas sustentáveis". Esses experimentos buscam articular nas escolas o currículo, a gestão e o espaço físico segundo princípios de sustentabilidade, inclusão e gestão participativa para exercitar um aprendizado que articule as habilidades cognitivas e afetivas com vivências exemplares e cotidianas através de práticas sustentáveis como a bioarquitetura, a gestão da água e da energia, o tratamento do lixo e o cultivo de árvores e hortas, entre outras possibilidades. 
O plano não formal - que reúne associações, movimentos sociais, organizações não governamentais, redes de movimentos e empresas - tem particularidades quanto a objetivos, conteúdos, espaços educativos e métodos. Contudo, também abre possibilidades promissoras na geração de saberes e práticas sustentáveis capazes de incluir no debate socioambiental outros setores da sociedade.

Jacobi et al. (2011), sistematizando as respostas educativas às mudanças climáticas em diversos países, revela uma tendência de abordagem da educação dirigida às mudanças climáticas como um campo independente da educação ambiental, com caráter cientificista pautado nas ciências do clima e em tópicos pontuais como emissões de carbono, variações de temperatura, inovação tecnológica, energia, transporte e reciclagem em detrimento das demais dimensões que constituem o problema. Ainda que se reconheça a necessidade de alguma alfabetização científica do tema, a presente reflexão entende que essa não seja a abordagem mais profícua. Entende, ao contrário, que o problema das mudanças climáticas é, na verdade, um subtema da educação e da crise socioambiental contemporânea e que só é possível acercar-nos delas através das múltiplas conexões políticas, ecológicas, culturais e econômicas que esclarecem suas causas e consequências.

A história da educação ambiental no Brasil assistiu, ao longo de seu desenvolvimento, a momentos de disputa e de conflitos entre concepções e práticas pedagógicas comportamentalistas e politizantes entendidos como modos antagônicos de perceber e reagir aos problemas socioambientais. Os comportamentalistas reduziam o desafio ambiental à órbita do indivíduo e da vida privada, entendendo que se cada um fizesse sua parte o problema seria resolvido. Os partidários do enfoque politizante, ao contrário, negavam a eficácia transformadora da ação comportamental - individual, ao priorizar a luta política de defesa do ambiente na esfera pública. Essa dicotomia sem síntese entre a micro e a macroexperiência, entre os aspectos individuais e sociais da mudança, parece hoje um falso dilema quando se considera a indissociabilidade entre indivíduos e sociedade. Não há indivíduos sem sociedade nem sociedade sem indivíduos. Esses dois entes que a percepção do senso comum e mesmo a teoria sociológica, historicamente, tratou dicotomicamente através de categorias relativamente independentes, estáticas e muitas vezes antagônicas - estrutura e ação social, sistema e ator social, micro e macrossociologia - não encontram evidência na observação empírica como bem demonstra a sociologia de Norberto Elias. Para o autor:

O que se tem costume de designar por dois conceitos diferentes, "o indivíduo" e "a sociedade", não constitui, como o emprego destes termos geralmente nos faz crer, dois objetos que existem separadamente, são, 
de fato, níveis diferentes, mas inseparáveis do universo humano (ELIAS, 1981, p. 156).

As mudanças do clima são reconhecidamente um problema público mundial que diz respeito a todos os humanos - além de afetar igualmente a vida não humana - e exigem respostas e soluções políticas, econômicas e culturais dos governos e organismos internacionais, dos movimentos sociais de todos os matizes, das empresas e dos centros de pesquisa, das mídias e dos educadores. Mas exigirá igualmente a participação, a mudança e a adaptação dos indivíduos. Do contrário, como transformar o paradigma de conhecimento sem o exercício individual dessa atitude na prática cotidiana? Como contestar a opressão econômica e política quando se reproduzem práticas opressivas nas relações pessoais, familiares e profissionais? Como defender uma sociedade ecológica quando se mantêm padrões de consumo ostensivos? Como operar transformações grandiosas quando ainda não foram transformadas as questões pequenas e próximas? Trata-se assim de superar a falsa dicotomia que separa os indivíduos da sociedade para reconhecer que precisamos de mudanças simultâneas e articuladas em todos os níveis e relações que afetam e se conectam com a existência humana.

Os desafios da governança global, em geral, e da governança ambiental e climática, em particular, advindos da atrofia e ambiguidade dos Estados e da expansão dos domínios do setor privado, têm colocado para a sociedade civil o desafio de fortalecimento da esfera pública e da participação democrática para conter os excessos das esferas governamentais e empresariais, processo que Habermas (1986) denominou de "Colonização do Mundo da Vida". No caso das mudanças climáticas temos assistido ao fracasso sucessivo dos esforços de negociação e de estabelecimento de uma agenda de compromissos para reverter ou minimizar o problema. Por essas razões a ampliação da cidadania ativa e da participação social são requisitos indispensáveis para o avanço e a difusão da educação e da cultura política, em especial, nos países periféricos de história mais recente e conturbada. Essa é uma tarefa urgente que os processos educativos podem ajudar a alavancar.

Em último lugar, ainda que não menos importante, aparece a carência de um suporte instrumental para que a educação ambiental e a problematização da crise climática possam prosperar. Essa tarefa não será possível sem a capacitação dos educadores, sem materiais didáticos adequados e adaptados ao contexto local, sem políticas públicas que reconheçam o papel da educação ambiental e sem a ambientalização e democratização das escolas, dos currículos e das práticas pedagógicas veiculadas. 


\section{Considerações finais}

O presente ensaio discutiu a complexidade da crise climática e as contribuições possíveis da educação ambiental nesse contexto. Defendeu o argumento de que a magnitude, a multidimensionalidade, a urgência e o alcance global da crise constituem mais que um impasse tecnológico, mas uma crise civilizatória que exige respostas ágeis e transformadoras em diversas dimensões da vida contemporânea.

Os múltiplos desafios dessa policrise e o cruzamento de suas implicações representam e refletem custos e benefícios econômicos, conflitos políticos, exigências institucionais, desigualdades sociais, impactos ambientais, modelos de desenvolvimento, produção e consumo e padrões ético-culturais e de conhecimento em escalas locais, regionais, nacionais e globais.

Por outro lado, o debate, as respostas e as políticas ambientais nos anos recentes têm assumido um perfil conservador, hegemonizado por orientações econômicas e técnicas, que estão longe de responder aos desafios colocados. Por isso os problemas ambientais crescem em escala geométrica ainda que a questão ambiental ganhe atenção crescente.

A defesa da superação do Conservadorismo Dinâmico se justifica perante a constatação de que a maior parte das respostas produzidas não tem isoladamente o poder de reverter o impasse climático ainda que possam ter alguma utilidade pontual ou mesmo uma função estratégica de grande relevância como é o caso da inovação tecnológica. Ou seja, são necessárias, mas insuficientes quando desarticuladas de outras mudanças políticas e culturais e de uma visão sistêmica do problema. Trata-se, portanto, de reconhecer que não há solução possível do impasse climático sem uma governança cooperativa, sem a incorporação de uma abordagem multidimensional não hegemonizada pelo econômico, sem o reconhecimento dos limites do crescimento e do consumo, sem uma distribuição justa e proporcional dos custos e responsabilidades entre os países e no interior de cada um deles e sem a renovação dos padrões culturais e valorativos inscritos nos modelos de produção e consumo.

Esse contexto põe em relevo as tarefas e os desafios da educação ambiental: reconhecer e problematizar a complexidade do problema, fazer a crítica do presente, de seus conflitos e oportunidades e construir saberes e práticas capazes dessa renovação. Essa contribuição educativa pode ser exercida tanto em contextos formais quanto não formais articulando o conhecimento do fenômeno com as ações cotidianas e locais e as esferas públicas e privadas de sua ocorrência. Isso vai exigir dos educadores e das comunidades educativas criatividade, responsabilidade solidária e participação democrática. 


\section{REFERÊNCIAS}

ABRAMOVAY, R. Desigualdades e limites deveriam estar no centro da Rio+20. Estudos Avançados, São Paulo, v. 26, n. 74, p. 21-33, jan./abr. 2012.

BECK, Ulrich. Risk Society. Beverly Hills: Sage, 1992.

BOURDIEU, P. Os usos sociais da ciência: por uma sociologia clínica do campo científico. São Paulo: Editora UNESP, 2004.

CARVALHO, I. C. de M. Educação ambiental: a formação do sujeito ecológico. São Paulo: Cortez, 2004.

DALY, H. Uneconomic Growth: in theory, in fact, in history, an in relation to globalization. In: DALY, Herman E. Ecological Economics and the Ecology of Economics: Essays in criticism. Cheltenham: Edward /Elgar. 1999. p. 8-24.

ELIAS, Norbert. Qu'est-ce que La sociologie? Paris: Pandora, 1981.

ESCOBAR, A. El "postdesarrollo" como concepto y práctica social. In: MATO, Daniel (Coord.). Politicas de economía, ambiente y sociedad en tiempos de globalización. Caracas: Facultad de Ciencias Económicas y Sociales, Universidad Central de Venezuela, 2005. p. 17-31.

FREIRE, P. Pedagogia da autonomia: saberes necessários à prática educativa. Rio de Janeiro: Paz e Terra, 2003.

GIDDENS, A. As conseqüencias da modernidade. São Paulo: UNESP, 1991.

. Sociologia. Porto Alegre: Artmed, 2005. 598 p.

. A política da mudança climática. Rio de Janeiro: Zahar, 2010.

GOHN, Maria da Glória. Educação não-formal, participação da sociedade civil e estruturas colegiadas nas escolas. Ensaio: Avaliação e Políticas Públicas em Educação. Rio de Janeiro, v. 14, n. 50, p. 27-38, jan./mar. 2006.

GUIMARÃES, Roberto P. O desafio político do desenvolvimento sustentado. Lua Nova, São Paulo, n. 35, p. 113-136, 1995.

HABERMAS, Jürgen. The theory of communicative action. Boston: Beacon Press, 1986.

HARVEY, D. Condição pós-moderna: uma pesquisa sobre as origens da mudança cultural. São Paulo: Loyola, 2012.

IPCC AR4/SPM. Contribution of Working Group I for the Fourth Assessment Report (AR4), Summary for Policy Makers (SPM), WMO/UNEP, Geneva, Switzerland, 2007.

JACOBI, Pedro Roberto et al. Mudanças climáticas globais: a resposta da educação. Revista Brasileira de Educação, Rio de Janeiro, v.16, n. 46, p. 135-148, jan./abr. 2011. LATOUCHE, Serge. O decrescimento. Por que e como? In: LÉNA, Philippe; NASCIMENTO, Elimar Pinheiro do (Orgs.). Enfrentando os limites do crescimento: sustentabilidade, decrescimento e prosperidade. Rio de Janeiro: Garamond, 2012. p. 45-54. 
LAYRARGUES, P. P.; LIMA, G. F. da C. As macrotendências político-pedagógicas da educação ambiental brasileira. Ambiente \& Sociedade, São Paulo v. XVII, n. 1, p. 23-40, jan./mar. 2014.

LEIS, Hector R. Globalização e democracia: Necessidade e oportunidade de um espaço público transnacional. Revista Brasileira de Ciências Sociais: ANPOCS, n. 28, 1995.

LIMA, G. F. da C. Mudanças climáticas e conservação social: riscos do aquecimento global. Gaia Scientia, João Pessoa, v. 3, n. 1, p. 35-46, 2009a.

. Educação ambiental crítica: do socioambientalismo às sociedades sustentáveis. Educação e Pesquisa, São Paulo, v. 35, n. 1, p. 145-163, jan./abr. 2009 b.

LIPIETZ, Alain. A ecologia política: solução para a crise da instância política? In: ALIMONDA, H. (ed.) Ecologia política. Buenos Aires: CLACSO, 2002. p. 15-26.

LITTLE, Paul Elliot. Ecologia política como etnografia: Um guia teórico e metodológico. Horizontes Antropológicos, Porto Alegre, ano 12, n. 25, p. 85-103, jan./jun. 2006.

MARENGO, José Antônio. Água e mudanças climáticas. Estudos Avançados, São Paulo, v. 22, n. 63, p. 83-96, maio/ago. 2008.

MORIN, Edgar (Org.). O problema epistemológico da complexidade. Portugal: Publicações Europa-América, 1996.

PORTILHO, Fátima. Sustentabilidade ambiental, consumo e cidadania. São Paulo: Cortez, 2005.

ROCKSTRÖM, J. et al. Planetary boundaries: exploring the safe operating space for humanity. Ecology and Society, v. 14, n. 2, p. 32, 2009.

SACHS, Jeffrey D. Comprender el 'impasse' climático. Tribuna, Laboratório de Idéias, 2010. Disponível em: <http://www.elpais.com/articulo/primer/plano/Comprender/ impasse/ climatico/elpepueconeg/20100822elpneglse_5/Tes>. Acesso em: 15/01/2012.

SCHON, Donald A. Beyond the stable state. New York: W.W. Norton, 1973.

SUNKEL, Os. Globalização, neoliberalismo e reforma do estado. In: PEREIRA, Luiz Carlos Bresser (Org.). Sociedade e estado em transformação. São Paulo: Ed. UNESP, Brasília: ENAP, 1999. p. 173-195.

VEIGA, José Eli da; ISSBERNER, Liz-Rejane. Decrescer crescendo. In: LÉNA, Philippe; NASCIMENTO, Elimar Pinheiro do (Orgs.). Enfrentando os limites do crescimento: sustentabilidade, decrescimento e prosperidade. Rio de Janeiro: Garamond, 2012.p. 107-134.

VIOLA, Eduardo; FRANCHINI, Matias. Sistema internacional de hegemonia conservadora: O fracasso da Rio +20 na governança dos limites planetários. Ambiente \& Sociedade, Campinas, v. xv, n. 3, p. 1-18, set./dez. 2012.

Texto recebido em 09 de outubro de 2014. Texto aprovado em 13 de outubro de 2014. 